\title{
MÉTODO 300 E SOCRATIVE: UMA EXPERIÊNCIA COM O USO DA METODOLOGIA ATIVA ALIADA À TECNOLOGIA NO CICLO BÁSICO DAS ENGENHARIAS
}

\author{
Pedro Paulo Sena Passos \\ Professor da Coordenação de Engenharia Elétrica da UNISUAM, Rio de Janeiro, RJ, Brasil \\ pedro.passos@unisuam.edu.br
}

\section{RESUMO}

As metodologias ativas vêm sendo centro de discussão para a implementação e aprimoramento por várias instituições de ensino. Uma delas é o "Método 300", criada em 2013 pelo Professor Ricardo Fragelli da Universidade de Brasília (UnB), motivado pelo alto índice de reprovação nas suas turmas de Cálculo 1 do ciclo básico das engenharias. Trate-se de uma metodologia baseada em aprendizagem ativa e colaborativa em que alunos que se destacam na primeira avaliação ajudam os que tiveram pior desempenho e são bonificados de acordo com o avanço dos integrantes da sua equipe. A utilização da tecnologia através do programa Socrative, classificado como uma das TICs (Tecnologias da informação e educação), tornou o método bem mais atrativo e dinâmico, pois os resultados das avaliações foram fornecidos instantaneamente. A experiência fornece a opinião dos alunos sobre as metodologias ativas através de pesquisa pelo Google Forms e os gráficos gerados pelo aplicativo. Os resultados são mostrados através de dados importados pelo Excel.

Palavras-chave: Método 300, metodologias ativas, ciclo básico das engenharias, tecnologia, socrative.

\section{METHOD AND SOCRATIVE: AN EXPERIENCE WITH THE USE OF ACTIVE METHODOLOGY ALLIED WITH TECHNOLOGY IN THE BASIC CYCLE OF ENGINEERING}

\begin{abstract}
Active methodologies have been the focus of discussion for implementation and improvement by several educational institutions. One of them is "Method 300", created in 2013 by Professor Ricardo Fragelli of the University of Brasilia (UnB), motivated by the high failure rate in his classes in Calculus 1 of the basic engineering cycle. It is a methodology based on active and collaborative learning in which students who stand out in the first assessment help those who had the worst performance and receive a bonus according to the progress of their team members. The use of technology through the Socrative program, classified as one of the ICTs (Information and Education Technologies), made the method much more attractive and dynamic, as the results of the assessments were provided instantly. The experience provides the students' opinion about the active methodologies through Google Forms search and the graphics generated by the application. Results are shown using data imported by Excel.
\end{abstract}

Keywords: Method 300, active methodologies, basic engineering cycle, technology, socrative. 


\section{INTRODUÇÃO}

As experiências com o Método 300 foram realizadas na IES, Centro Universitário Augusto Motta (UNISUAM), localizada na zona norte da cidade do Rio de Janeiro, com uma turma de Introdução ao Cálculo do ciclo básico das engenharias no primeiro semestre de 2019. A disciplina é composta por conteúdos de matemática do Ensino Médio que servem como pré-requisitos para a disciplina de Cálculo 1. A utilização de métodos tradicionais de ensino para disciplinas cuja essência é a matemática abstrata exclui estudantes que, por algum motivo, têm dificuldade na absorção dos conteúdos, por isso foi tomada a decisão de aplicar uma das Metodologias Ativas nesta turma.

\section{DESENVOLVIMENTO}

2.10 ensino através de metodologias ativas

Entre as causas que contribuem com a evasão nos cursos de Engenharia, destaca-se a de ordem pedagógica (ALMEIDA; GODOY, 2016). O uso de Metodologias Ativas objetiva a reversão dessa perspectiva.

A UNISUAM recebe muitos alunos da rede pública de ensino ou que já atuam no ramo das engenharias e retomam os estudos a fim de evoluir nas suas carreiras profissionais, porém acabam encontrando dificuldades na matemática básica, devido à baixa qualidade do ensino púbico ou ao tempo de ociosidade nos estudos.

O ensino no Rio de Janeiro ainda ocorre, predominantemente, de forma tradicional. Tal fator influencia diretamente no processo educacional. A pouca relação entre o que é ensinado e o mercado de trabalho e a insistência no modelo tradicional de ensino dificultam o processo de aprendizagem (FRAGELLI, 2015). As Metodologias ativas criam um ambiente mais humanizado e as aulas ocorrem de maneira colaborativa, reproduzindo competências que os futuros Engenheiros terão que obter para sua colocação, manutenção ou realocação no mercado de trabalho. Portanto, o principal objetivo da experiência, além do nivelamento dos conteúdos matemáticos, é a postura de emparia e colaboração que os alunos necessitam desenvolver, a fim de que possam lidar com as pressões e diferenças que encontrarão em um mercado de trabalho cada vez mais competitivo. 


\subsection{A metodologia "Método 300" e o software "Socrative"}

Historicamente, as disciplinas de Introdução ao Cálculo e Cálculo 1, do ciclo básico das engenharias da UNISUAM são as que possuem os maiores índices de reprovação. Isso ocorre devido aos déficits de aprendizagem nos conteúdos elementares da matemática. Após os resultados insatisfatórios da primeira avaliação, surgiu a ideia de aplicar a metodologia de ensino, “Método 300", antes já apresentada aos professores da instituição, no Simpósio Docente deste ano. A essência do método é promover ao máximo a colaboração entre os estudantes, despertando o olhar para as dificuldades de aprendizagem do outro (FRAGELLI, 2015). Para isso, forma-se grupo de estudos contendo, necessariamente, um aluno que tenha tido um bom desempenho em uma avaliação e um que tenha tido desempenho insatisfatório. Os discentes que tiveram desempenho insatisfatório são submetidos a uma nova avaliação, havendo melhora seu grau é aumentado e o aluno ajudante do grupo (líder), também é bonificado.

A metodologia foi iniciada a partir da vista de prova após a verificação de que 16 dos 28 alunos efetivamente avaliados tinham obtido o grau inferior à média da IES (seis pontos) para a aprovação na disciplina, ou seja, aproximadamente 57\% de notas insatisfatórias.

Figura 1 - Gráfico representativo dos resultados das avaliações A1 na turma de Introdução ao Cálculo pelo Excel

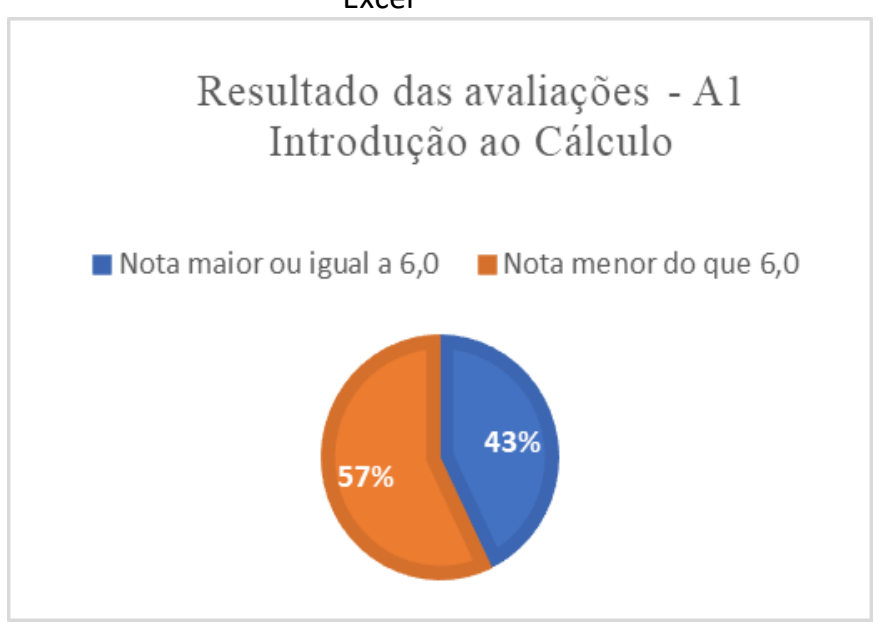

Fonte: Autoria própria

Os alunos foram notificados que haveria uma atividade em grupo pelo "Google Classroom" (Google sala de aula), que é utilizada pela instituição para a aplicação das APS (atividade prática supervisionada), portanto, os discentes já sabiam que ocorreria um trabalho em grupo, mas sem saber da natureza da atividade. As questões com maior incidência de erros foram reformuladas e os alunos organizados em equipes compostas de 3 a 5 integrantes, fora do formato tradicional, e 
os integrantes com melhores desempenhos na primeira avaliação semestral foram denominados, a partir desta aula, de monitor, em conformidade aos pressupostos do método 300 .

Figura 2 - Estudantes do 1o período de Introdução ao Cálculo durante a aplicação do Método 300

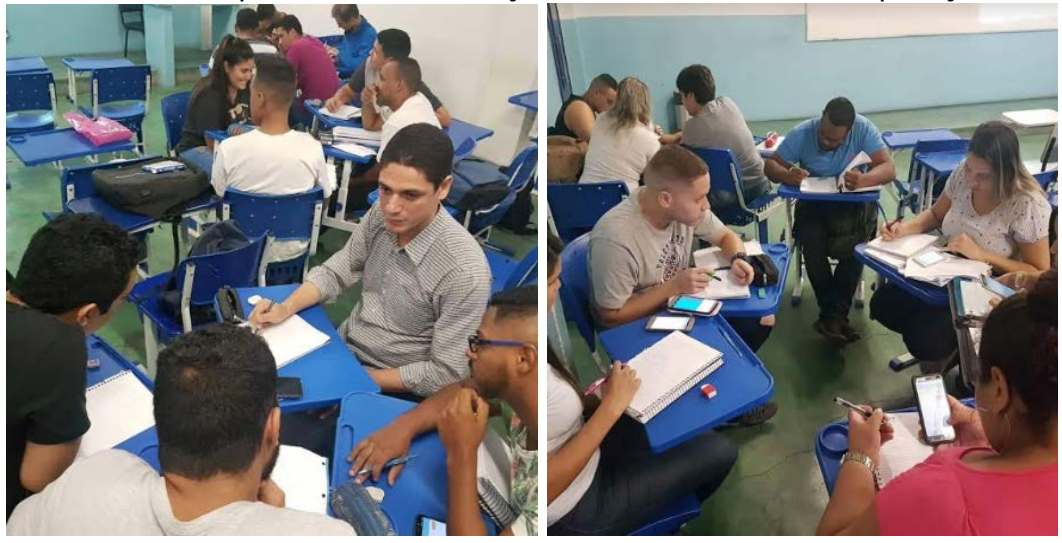

Fonte: Autoria própria

O software "Socrative" foi escolhido como recuso tecnológico incentivador e facilitador da experiência, por fornecer a possibilidade de uma avaliação instantânea, necessitando apenas de um aluno com acesso à internet, já que se travava de uma aula onde os alunos utilizariam a aprendizagem colaborativa. Através do aplicativo, os estudantes tiveram acesso aos resultados no final da aula pelo próprio programa e o feedback sobre os erros de uma equipe puderam ser reportados no mesmo dia.

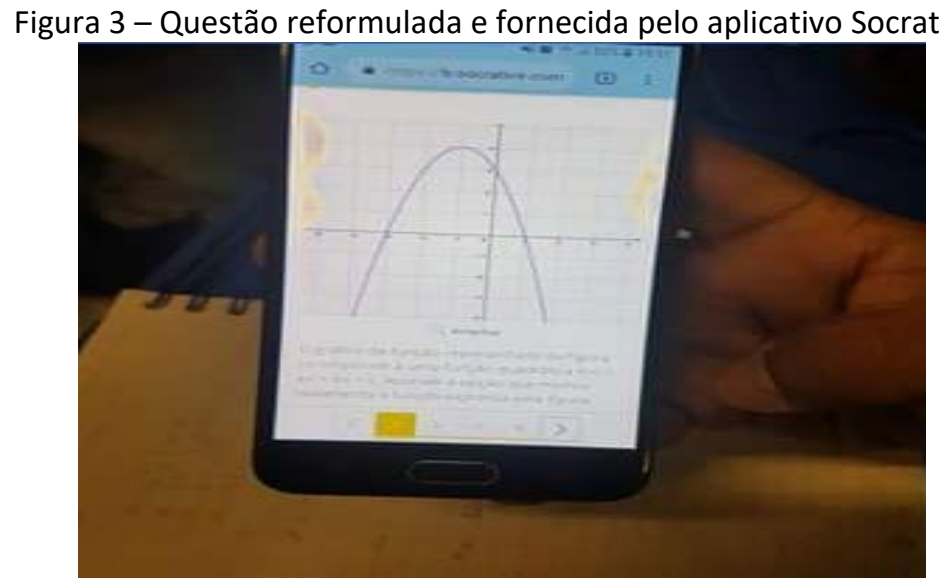

Fonte: Autoria própria

A execução desta metodologia modificou o comportamento da turma. Os alunos se mostraram entusiasmados após a aplicação do método associado à tecnologia educacional, começando a criar grupos de estudos através das suas redes sociais. Alguns pediram auxílio para utilizar o Socrative em atividades profissionais, visto que o software também é utilizado em ambientes coorporativos, tornando o impacto da atividade ainda mais positivo. 


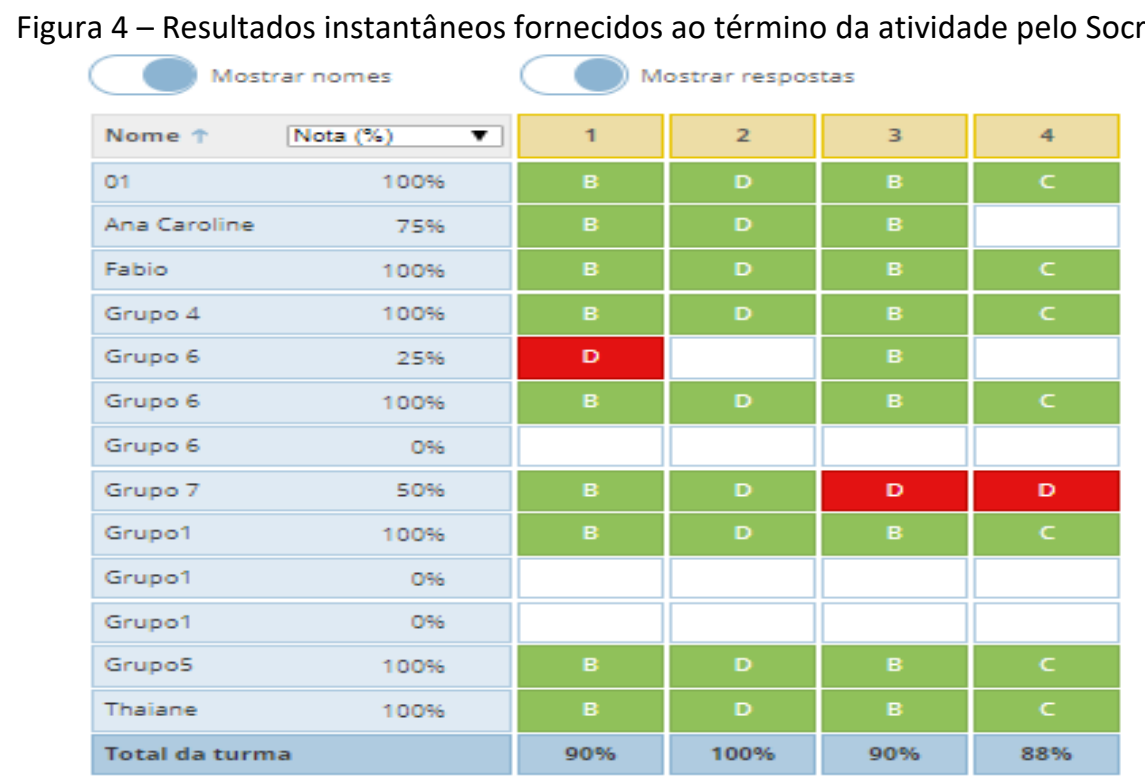

Fonte: Autoria própria

2.3 Avaliação da aprendizagem

Uma das habilidades esperadas através das aulas com metodologias ativas é o desenvolvimento da autonomia dos discentes na resolução dos problemas, dessa forma, o professor procurou verificar quais eram as maiores dificuldades que os alunos tiveram na realização da primeira avaliação percorrendo a sala de aula e a interagindo com monitores de cada grupo, incentivando-os a sanarem qualquer dúvida que surgisse entre os integrantes das equipes. Portanto, além do retorno online oferecido pelo aplicativo o professor/orientador procurou responder somente as dúvidas que eram indispensáveis, proporcionando um ambiente colaborativo e aumento de empatia entre os alunos da turma.

\subsection{Resultados}

Os resultados qualitativos foram verificados através de pesquisa no Google Forms e os quantitativos, através de gráficos no Excel.

Quatorze alunos responderam perguntas sobre a aplicação do Método, sobre as metodologias ativas em geral e sobre a utilização do Socrative como facilitador das experiências. As perguntas foram elaboradas em uma escala crescente de 1 a 5 , onde 1 é péssimo e 5 excelente. 
Figura 5 - Avaliação dos estudantes sobre as experiências com o Método 300 pelo Google Forms

Como você avalia as experiências com o Método 300 na turma de Introdução ao Cálculo?

14 respostas

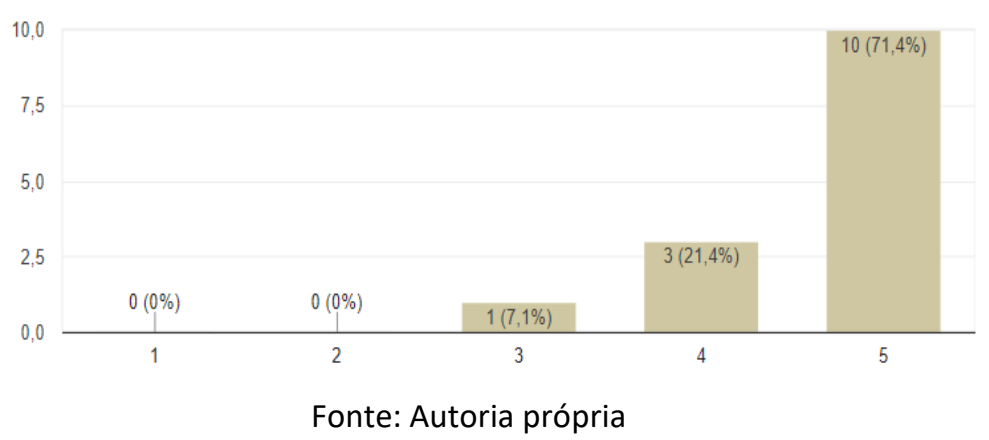

Nota-se que $92,8 \%$ dos entrevistados avaliou o Método 300 como excelente ou bom, 7,1\% regular e não houve nenhuma avaliação negativa sobre as experiências.

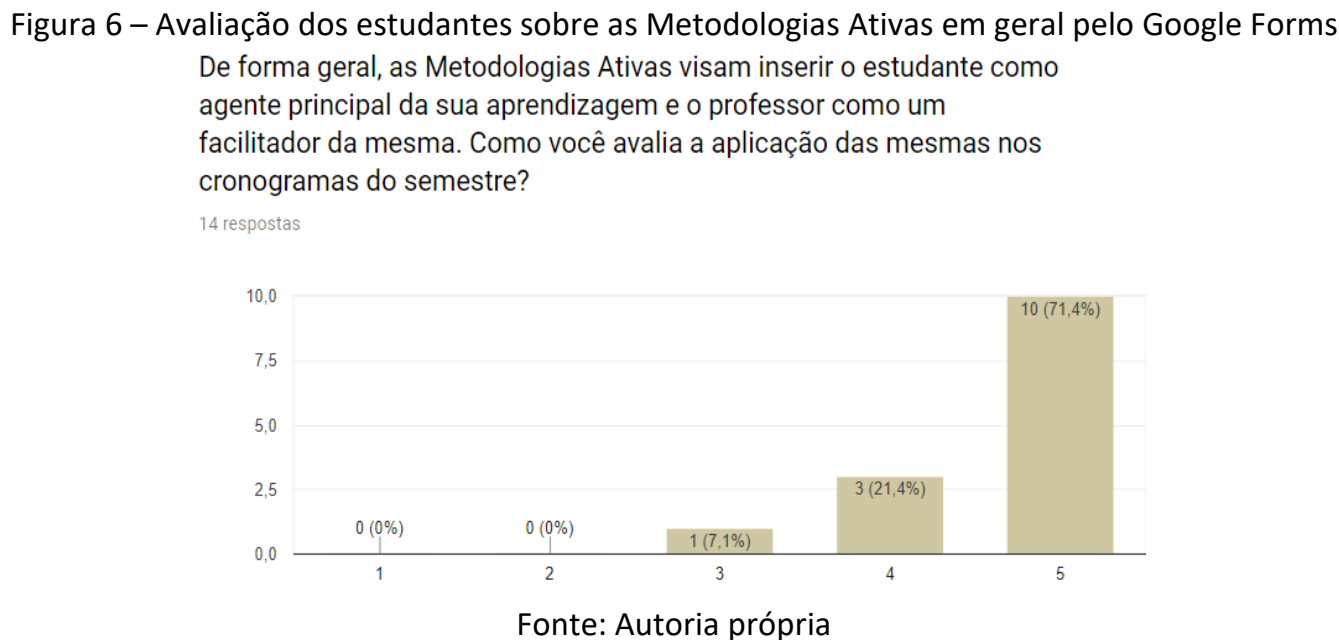

Os resultados da pesquisa sobre a inclusão de Metodologias Ativas nos cronogramas do semestre foram idênticos à da aplicação do Método 300.

Figura 7. Avaliação dos estudantes sobre o programa Socrative pelo Google Forms Para aplicação do Método 300, utilizamos o programa "Socrative", que é um software interativo classificado entre uma das TICs (tecnologias da informação e comunicação). Como você avalia o aplicativo?

14 respostas

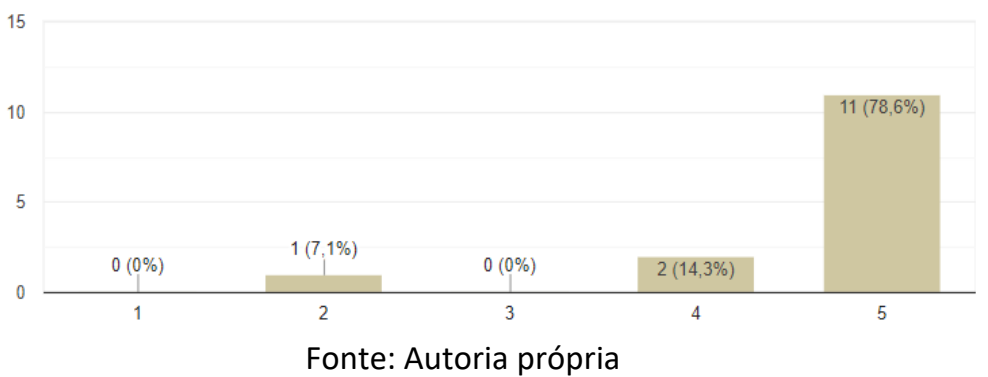

\begin{tabular}{l|l|l|l|l|l|l|} 
Projectus & Rio de Janeiro & V.5 & N. 1 & P.75-83 & 2020
\end{tabular} 
Nota-se que $92,9 \%$ dos estudantes avaliaram a ferramenta Socrative como excelente ou boa e apenas 7,1\% (1 aluno) não gostaram do aplicativo.

Alguns comentários sobre a experiência também foram registrados na pesquisa que reforçam a aprendizagem significativa obtida através das experiências:

"O método 300 foi uma experiência excelente pois foi fácil a aprendizagem em grupo e a participação de todos é maior."

"Excelente, deixa o aluno mais solto possibilitando tirar todas as dúvidas, sem precisar ter vergonha, coisa que acontece muito com aluno tímido, que não pergunta ou professor na hora da explicação."

"Achei a aplicação excelente. Método que faz aproximação dos alunos em que uns auxiliam os outros na resolução dos exercícios."

"A utilização do Socrative foi muito boa, pois podemos debater nossas opiniões sobre os exercícios e assim chegar a uma conclusão."

"Uma ótima ferramenta, que foi explorada de maneira perfeita. Juntando o útil ao agradável. Como somos conectados com a Internet, o professor trouxe uma forma de brincar e aprender ao mesmo tempo."

"Deveria ser utilizado por mais professores."

Ao final das experiências e com posse de todos os resultados obtidos nas três avaliações semestrais, verificou-se uma melhora significativa em relação aos resultados da primeira avaliação dos vinte sete alunos avaliados. Vinte conseguiram a aprovação na disciplina, o que corresponde a um percentual de aproximadamente $74 \%$, melhorando consideravelmente os resultados em relação à primeira avaliação sem a aplicação de metodologias ativas.

Figura 8. Gráfico representativo da quantidade de estudantes aprovados e reprovados na disciplina de Introdução ao Cálculo pelo Excel

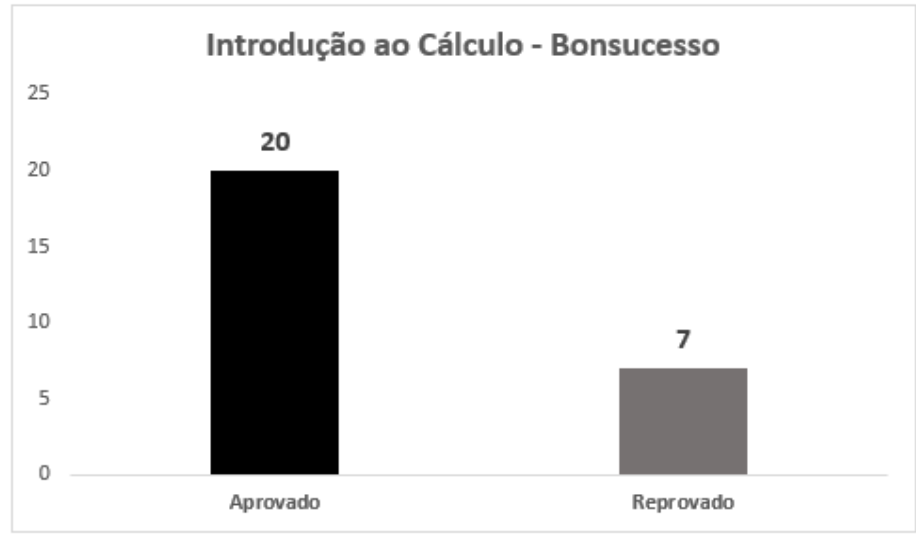

Fonte: Autoria própria 
Os resultados apresentados desconsideram alunos que evadiram por algum motivo, servindo apenas para ilustrar a melhoria do desempenho dos que permaneceram até o final do semestre após a aplicação do Método 300.

\subsection{Dificuldades encontradas}

A principal dificuldade ocorreu devido aos atrasos dos alunos nas aulas, visto que a IES é localizada na zona norte do Rio de Janeiro e as aulas começam às 18h30, horário de "rush" na cidade, porém os alunos já haviam estabelecido contato através das suas redes sociais e os líderes ajudaram os colegas de equipes até a última avaliação e em razão da melhora significativa no desempenho da turma foram bonificados com um ponto extra. Apenas um aluno muito introspectivo pediu para não participar das experiências. Espera-se que ao longo dos próximos semestres, ele possa repensar sobre sua participação nas metodologias ativas, já que as habilidades adquiridas através dessas experiências certamente o ajudarão a ser profissional completo dentro da sua área de formação.

\section{CONSIDERAÇÕES FINAIS}

A implementação das experiências com o Método 300 na turma de Introdução ao Cálculo mudou a postura não apenas dos estudantes envolvidos, mas também dos docentes que começaram a rever suas metodologias de ensino, visto que os estudantes propagaram as boas práticas vividas ao longo do semestre para os discentes, docentes e coordenadores. A UNISUAM vem investindo cada vez mais na capacitação de professores com o objetivo de que as aulas exclusivamente expositivas sejam enriquecidas com metodologias ativas que desenvolvam competências como: resiliência, foco em resultados, espírito empreendedor, empatia, cooperação, autoconhecimento e agilidade em tomadas de decisões (BNCC, 2018). É importante que o docente se atualize de forma que insira o aluno como agente principal da sua aprendizagem e o professor como um facilitador deste processo. 


\section{REFERÊNCIAS}

ALMEIDA, Eustáquio; UNIVERSIDADE CRUZEIRO DO SUL. A Evasão nos cursos de Engenharia e a sua relação com a Matemática: uma análise a partir do COBENGE, 2016. 101 p, Dissertação (Mestrado).

BASE NACIONAL COMUM CURRICULAR. O uso de metodologias ativas colaborativas e a formação de competências. Disponível em:

$<$ http://basenacionalcomum.mec.gov.br/implementacao/praticas/caderno-de praticas/aprofundamentos/202-o-uso-de-metodologias-ativas-colaborativas-e-a-formacao-decompetencias2?highlight=WyJtZXRvZG9sb2dpYXMiLCJhdGI2YXMiLCJtZXRvZG9sb2dpYXMgYXRpdm FzllO=>. Acesso em: 15 jul. 2019.

FRAGELLI, R. R. Trezentos: Aprendizagem colaborativa como uma alternativa ao problema da ansiedade em provas. Revista Eletrônica Gestão \& Saúde, Brasília, v. 6, supl. 2, p. 860-872, abr. 2015.

PASSOS, P. P. S. Metodologias Ativas e Tecnologia: Uma proposta de aula sobre tópicos contextualizados de Função Quadrática com o auxílio do programa Socrative. Dissertação (Mestrado profissional em Matemática), Universidade Federal do Estado do Rio de Janeiro, Rio de Janeiro, 2017. 